\title{
Report of Breakout Group 1. What Kind of Training do Plant Breeders Need, and How Can We Most Effectively Provide that Training?
}

\author{
Callista Ransom \\ Department of Crop and Soil Sciences, Michigan State University, East Lansing, MI 48824 \\ Chrislyn Particka, Kaori Ando, and Jim Olmstead \\ Department of Horticulture, Michigan State University, East Lansing, MI 48824
}

Before beginning a discussion about the future of plant breeding training, it is necessary to define what a plant breeder is. The traditional view of plant breeders includes only those researchers who develop new plants that result in a product more suited to human needs. However, many feel that this definition should be expanded to include scientists who contribute to crop improvement through any type of genetic studies. These studies range from using molecular markers to describe levels of diversity in a breeding population to identifying the QTL that underlie variation patterns. In this discussion of plant breeding training we will use the more restricted definition to single out the training of those individuals who directly produce new cultivars.

Training of PhD level plant breeders. Between 1995 and 2000, 40 universities in the U.S. reported that they had trained graduate students in plant breeding (Guner and Wehner, 2003). The existing programs appear to be producing sufficient numbers of PhD plant breeders to fill the needs of the private and public sectors today, but there is increasing global worry about the future. The number of public breeders in Universities is significantly declining, resulting in fewer students being trained. There is also concern that as public plant breeders retire, they are being replaced by scientists involved in more basic genetic studies. This shift will make it increasingly difficult for students to get hands-on breeding experience with someone who is active in the field.

Acomplete PhD curriculum for plant breeders includes a set of required, core courses that contain information all plant breeders need and a smorgasbord of relevant, elective courses that are targeted towards the specific interests of students (Table 1). The core set of courses should include experimental design, applied statistics, Mendelian/transmission genetics, population and quantitative genetics, and principles and practices of plant breeding. Useful electives range across disciplines from business management to crop ecology to molecular biology.

There are also a number of attitudes and skills that make a person a successful plant breeder, which are not necessarily learned in course work (Table 2). These are talents inherent to one's personality that cannot necessarily be learned, but can be improved upon, such as creativity, sense of mission and decisiveness. There are also special skills that can be learned both inside and outside of the class room such as grantsmanship, teaching competence, budget management, human resource management and fluency in foreign languages.

Plant breeding training programs need to be broad enough to generate $\mathrm{PhD}$ graduates who meet the expectations of the private and public sectors, since $2 / 3$ of plant breeders are now employed by the private sector (Bliss, 2006). The private sector seeks graduates with strong, applied breeding experience, working knowledge of molecular and genomic techniques, and business skills such as administrative organization, budgeting and intellectual property management. Public breeders are expected to be well versed in molecular and genomic techniques, be adept at publishing refereed journal articles, and have superior grantsmanship. All breeders must be proficient in data management and be comfortable with the growing ethical, legal, and social issues associated with globalization.

Understanding how molecular genetics can be incorporated into traditional breeding programs is one of the most important, new expectations of plant breeders in both the public and private sectors. Plant breeders in the public sector, especially those that are newly hired, are expected to construct breeding programs that use both conventional and molecular techniques, with the emphasis on molecular approaches. Plant breeders in the private sector are not expected to conduct research using molecular technologies themselves, but it is anticipated that they will work as a member of a team that includes molecular biologists (Bliss, 2006). The challenge in the future will be to produce $\mathrm{PhDs}$ that have a solid background in plant molecular biology and know how to run a breeding program. This will require that active plant breeders are maintained at public universities.

Adaptations that need to be made in PhD curricula. There are a number of ways that plant breeding curricula should be adapted to incorporate emerging technologies. More time in courses should be devoted to molecular mechanisms, bioinformatics, genomics, proteomics, and metabolomics, so that all plant breeders are sufficiently versed in these areas to take advantage of their applications. In addition, more attention should be devoted to the ethical, legal and social issues that are associated with globalization and the growing need to protect intellectual property.

Given that more time should be spent on these emerging subjects, there will be the temptation to give some traditional topics less emphasis, such as cytogenetics, population genetics and quantitative genetics. However, care must be taken to still provide the core knowledge necessary to be a plant breeder. Strong efforts must be made to incorporate the emerging material into the traditional breeding courses as much as possible, rather than just adding new courses. For example, the elements of QTL analysis should be described within the framework of a quantitative genetics course, and marker assisted selection should be a component of a course describing the principles and practices of plant breeding. It is also critical that all breeding students get some hands-on experience in field techniques, so they will feel comfortable in directing a breeding program.

Other types of plant breeding training. The development of more BS degree programs in plant breeding is encouraged, as there is considerable need for hands-on breeders in private industry with good crop knowledge. To interest students at this level in plant breeding, introductory courses should be innovative and taught by passionate plant breeders, and opportunities for international experience, mentoring programs and internships should

Table 1. Course components of a complete graduate program in plant breeding.

\begin{tabular}{ll}
\hline Core courses & Supplementary courses \\
\hline Experimental design and applied statistics & Business management \\
Mendelian/transmission genetics & Crop agronomy \\
Population genetics & Crop evolution \\
Principles and practices of plant breeding & Crop physiology \\
Quantitative genetics and selection theory & Ecosystem management \\
& Entomology \\
& Intellectual property rights \\
& Genomics \\
& Language \\
& Molecular biology \\
& Plant pathology \\
& Plant reproductive biology \\
\hline
\end{tabular}


Table 2. Talents and skills needed by the successful plant breeder.

Essential talents and skills

Adaptiveness

Creativity

Cross-cultural awareness and sensitivity

Decisiveness

Quantitative thinking

Scientifically curious

Sense of mission/purpose

Interpersonal skills/team worker
Useful talents and skills

Budget management

Communication

Critical thinking

Human resource management

Leadership

Multi-lingual

Multi-tasking

Negotiation

Observation

Priority setting

Teaching be promoted. A specialization in plant breeding could be incorporated into BS degrees in agronomy, horticulture or forestry. The core classes for a BS degree would therefore include crop agronomy production and biology, as well as basic statistics, principles, and practices of plant breeding, and genetics. Plant pathology, entomology, and ecosystem management would be included in the elective courses for a BS-trained plant breeder.
Universities could also greatly aid the private sector, if they develop professional master's degree programs for active private breeders. These programs will require different modes of delivery from traditional training, both in format and timing, with the information presented in a condensed format at a time convenient for the private sector breeders. The course offerings would be very similar to the $\mathrm{PhD}$, but without an extensive thesis requirement.

The private sector would also welcome short courses on emerging breeding topics and technologies, as has been done at the IARCs for international breeders (Khush, this symposium). These types of courses would not only update the private breeders, but would facilitate interaction between the public and private sector. 